\title{
APLICAÇÃO DA METODOLOGIA PM CANVAS EM PROJETOS DE REABILITAÇÃO DE PATOLOGIAS DAS CONSTRUÇÕES
}

\author{
VERONEZ, MARCELO \\ Engenheiro Civil, MSc. \\ Consultor Especialista em Eng ${ }^{\mathrm{a}}$ de Patologia das Construções \\ Espírito Santo; Brasil \\ mveronez@hotmail.com
}

\section{RESUMO}

O processo de reabilitação das patologias das construções obedece a uma sistemática que passa pelo diagnóstico $x$ prognóstico $x$ tratamento, no qual uma série de decisões devem ser tomadas. Na etapa do projeto da reabilitação, p.e., pode-se decidir desde a ampliação ou a redução do escopo e da abrangência da intervenção física, até uma possível condenação do elemento da construção em estudo. As decisões neste momento dependem de uma série de fatores técnicos e de gestão, dentre os quais pode-se observar a ferramenta de gestão que é utilizada no processo de projeto da reabilitação. Este trabalho apresenta exemplos da aplicação da metodologia Project Model Canvas - PM Canvas - na elaboração de projetos de reabilitação de patologias das construções. Estão apresentadas 3 Telas que resumem o processo de reabilitação para 3 tipos de patologias das construções. Em seguida estão apresentados e discutidos os detalhes avaliados com a ferramenta PM Canvas em cada uma das propostas de reabilitação.

Palavras-chave: pm canvas, metodologia, patologia das construções.

\section{ABSTRACT}

The process of rehabilitation of building pathologies follows a systematic that goes through diagnosis $\mathrm{x}$ prognosis $\mathrm{x}$ treatment, in which a series of decisions must be made. At the stage of the rehabilitation design, for example, it can be decided from extending or reducing the scope of physical intervention to the possible condemnation of the building element under study. Decisions at this time depend on several technical and management factors, including the management tool that is used in the rehabilitation design process. This paper presents examples of the application of the Project Model Canvas methodology - PM Canvas - in the elaboration of construction pathology rehabilitation designs. There are 3 Canvas that summarize the rehabilitation process for 3 types of building pathologies. Following are presented and discussed the details evaluated with the PM Canvas tool in each of the rehabilitation proposals. Keywords: pm canvas, methodology, building pathology.

\section{INTRODUÇÃO}

Quando se avalia a concepção e produção de um produto ou serviço, fala-se muito em projetos, quase tudo que se propõe a realizar é um projeto; e mesmo sem o contato direto com projetos ou com a gestão dos projetos, é importante se ter a noção do que é um projeto e de como ele é estruturado (CIERCO et al., 2011; VARGAS, 2018). O objetivo deste trabalho é de forma simples passar algumas definições de projeto com aplicação de uma metodologia inovadora no processo de reabilitação das patologias das construções.

Um projeto, segundo o Guia PMBOK® 2018 é “um esforço temporário empreendido para criar um produto, serviço ou resultado exclusivo. Os projetos e as operações diferem, principalmente, no fato de que os projetos são temporários e exclusivos, enquanto as operações são contínuas e repetitivas." (PMI, 2018). Assim entendido, um projeto é o evento que necessariamente tem início e fim, um escopo (o que vai ser realizado), todos bem definidos, ao contrário de uma operação, que se trata de algo rotineiro, por exemplo, uma tarefa diária a qual não se sabe ao certo até quando ela será necessária, e quando deve deixar de ser realizada. Neste sentido da discussão, este trabalho trata do processo de reabilitação de uma patologia como sendo um evento programado com escopo bem definido e diferente para cada ocasião a ser empregado, com início e fim delimitados, sendo possível que seam empregados os métodos de gerenciamento de projetos, segundo o PMI (2018). 
A escolha da metodologia de gerenciamento de projeto mais adequada deve ser realizada caso a caso, de acordo com as características de cada projeto, das escolhas do patrocinador, das tecnologias envolvidas, da cultura organizaciona, e das partes interessadas (VARGAS, 2018). Atualmente é comum a adoção de uma "metodologia híbrida" que se caracteriza pela combinação de princípios, de práticas, e de técnicas e ferramentas de duas ou mais metodologias consagradas com a finalidade de melhor adequar a gestão do projeto ao contexto do negócio e proporcionar o melhor equilíbrio entre a flexibilidade e a previsibilidade no acompanhamento, mitigando os riscos do projeto e possibilitando a incorporação de inovação aos seus processos (HARVARD BUSINESS REVIEW, 2015; PMI, 2018). Via de regra, ao adotar uma "metodologia híbrida" como estratégia de alcance dos objetivos do projeto, a empresa busca uma solução para a elaboração e execução de seus projetos que conduza ao desenvolvimento de novas competências internas, propondo soluções ágeis e de baixo consumo de recursos, utilizando os seus recursos já disponíveis (VARGAS, 2018).

A "metodologia híbrida" de gerenciamento de projetos, então, é basicamente uma combinação de duas outras metodologias utilizada para criar um terceiro modelo novo e mas adequado para a condição de um projeto. A bibliografia está repleta de metodologias, desde o Modelo em Cascata até o Modelo Ágil, passando pelos Métodos Visuais, pelo PRINCE2 e pelo Guia PMBOK® (CIERCO et al., 2011). As novas metodologias, como os Modelos Ágeis, constantemente desenvolvidas buscam desafiar os tradicionais, e as "metodologias híbridas" podem proporcionar a sinergia na combinação de alguns destes métodos, sejam eles novos ou tradicionais. A "metodologia híbrida" assimila a fluidez do projeto e permite uma abordagem que pode ser mais ágil e detalhada. Ela é aplicável ao projeto por ou a um ou mais de seus segmentos. A principal vantagem da utilização da "metodologia híbrida" é que, quanto mais maneiras houver de abordar um problema, maior será a chance de resolvê-lo.

O Modelo em Cascata é uma metodologia tradicional de gerenciamento de projetos, que utiliza da Estrutura Analítica de Projetos (EAP) para gerenciar projetos complexos. Ela se trata de um modelo clássico, no qual o Gerente do Projeto e as Partes Interessadas se preocupam em ver custos fixos e cronogramas, e geralmente é usada para grandes projetos de infraestrutura, pontes, túneis, etc. (CIERCO et al., 2011). O fluxo de planejamento define que antes de se iniciar o projeto, deve ser planejado tudo o que deve ser ser realizado e, em seguida, as partes ou tarefas do planejamento são divididas em partes menores ou subtarefas, e o processo avança até que cada tarefa esteja pequena o suficiente para que esteja bem definida (HARVARD BUSINESS REVIEW, 2015; PMI, 2018). Esta é a metodologia historicamente mais adotada nos empreendimentos da construção civil, e por consequencia do hábito da sua utilização, é a maneira típca de se visualizar também as atividades de um processo de reabilitação das patologias das construções.

As metodologias baseadas nos Métodos Visuais utilizam do processo de visualizar a informação, que se relaciona com o transformar do abstrato em imagem mental ou real, imagem esta que pode ser visualizada por outras pessoas, auxiliando no entendimento de um determinado assunto (OSTERWALDER, 2011; CAMARGO, 2019). Os Métodos Visuais objetivam extrair o máximo de informação de um volume de dados e apresentar de forma clara e concisa, utilizando metáforas visuais. Visualizar a informação permite processar um grande volume de dados, a partir da capacidade de percepção visual, exigindo uma menor capacidade cognitiva. A boa visualização potencializa a clara compreensão e aumenta a quantidade de informação que pode ser "compreendida" e "apreendida" e, assim, os projetistas, os gerentes, os tomadores de decisão, e outras partes interessadas, podem concentrar mais a atenção cognitiva e perceptiva para o raciocínio analítico ou criativo a partir da visualização das informações (FINOCCHIO JUNIOR, 2013). A Figura 1 aprsenta as ferramentas utilizadas nos Modelos Visuais de gestão de projetos.

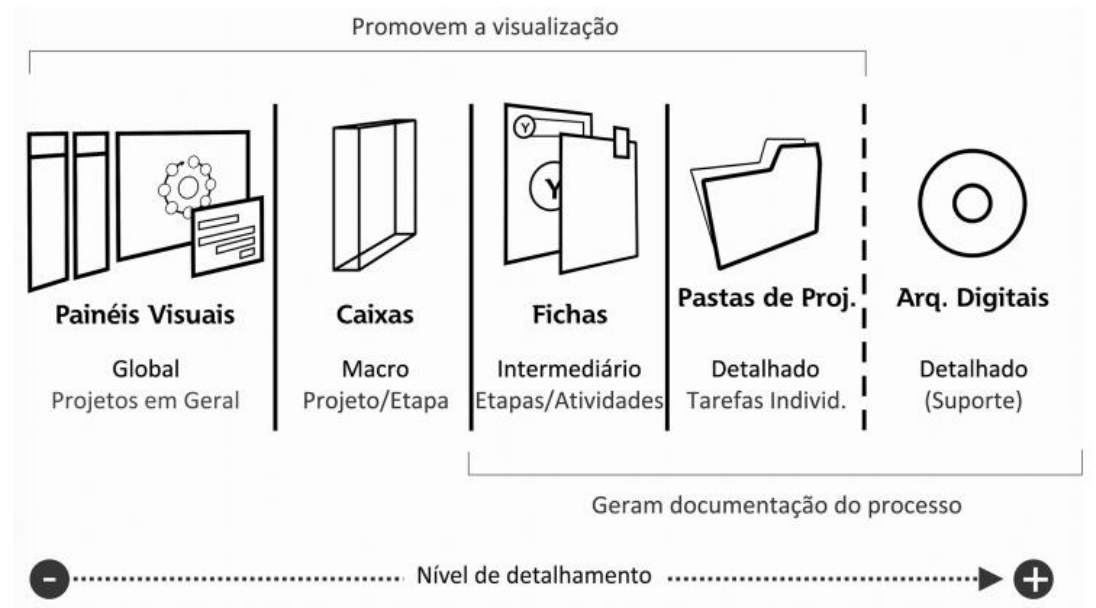

Figura 1: Ferramentas dos Modelos Visuais de gestão de projetos (TEIXEIRA e MERINO, 2014) 
A proposta deste trabalho é de apresentar a utilização de uma "metodologia híbrida" para o gerenciamento do processo de reabilitação das patologias das construções, utilizando duas outras metodologias baseadas nos Métodos Visuais, que sejam o Project Model Canvas (PM Canvas) e o Kanban, e dentro da proposição realizada, apresentar exemplos da aplicação da metodologia PM Canvas - na elaboração de projetos de reabilitação de patologias das construções. O PM Canvas é uma ferramenta de planejamento, e o Kanban é uma ferramenta de controle da execução que, igualmente, utiliza dos Métodos Visuais. Neste sentido, as duas ferramentas se completam muito bem, primeiro fazendo o planejamento do projeto no PM Canvas e em seguida o controle da execução no Kanban (VERONEZ, 2019). Uma explicação bem simples desta integração foi apresentada no canal de YouTube do prof. José Finocchio, que estabeleceu o processo de utilização do PM Canvas, a partir do Business Model Canvas, uma outra metodologia que utiliza dos métodos Visuais (FINOCCHIO JUNIOR, 2018).

\subsection{A utilização do PM Canvas}

O PM Canvas é uma ferramenta simples e rápida de ser executada, utilizando as questões essenciais, que fazem parte de qualquer projeto. Ela foi inspirada no Business Model Canvas, um outro modelo que facilita a visualização do todo de um modelo de negócio, concebendo o projeto em uma página. O PM Canvas e o Business Model Canvas são baseados em princípios da Neurociência, quais sejam:

1. de simplificar;

2. de agrupar;

3. de que o cérebro tem capacidade visual maior que de linguagem;

4. de engajar stakeholders.

O principal motivo para a adoção destas técnicas, segundo Finocchio Junior (2013), é que ninguém consegue ter na cabeça um projeto completo, apenas partes ou modelos de projeto. Um modelo mental do projeto é formado por conceitos - como recursos, stakeholders, entregas, riscos - pelas relações entre esses conceitos. Nele, deve-se ser simples, mas não simplista, ou seja, buscar a essência das coisas sem, no entanto, deixar de observar todos os aspectos necessários. Esse deve ser o objetivo de todo bom gestor e consequentemente de um bom gerente de projetos, onde por natureza já há muitas variáveis a serem conduzidas.

A utilização do PM Canvas demanda pouco, basta que alguém possua à mão uma folha e aqueles pequenos papéis adesivos conhecidos como post-its. Naturalmente, o mais indicado seria um flip chart em formato, para uma abordagem bem colaborativa, ou um processo informatizado. A Figura 2 apresenta a tela (ou canvas) utilizada neste método.

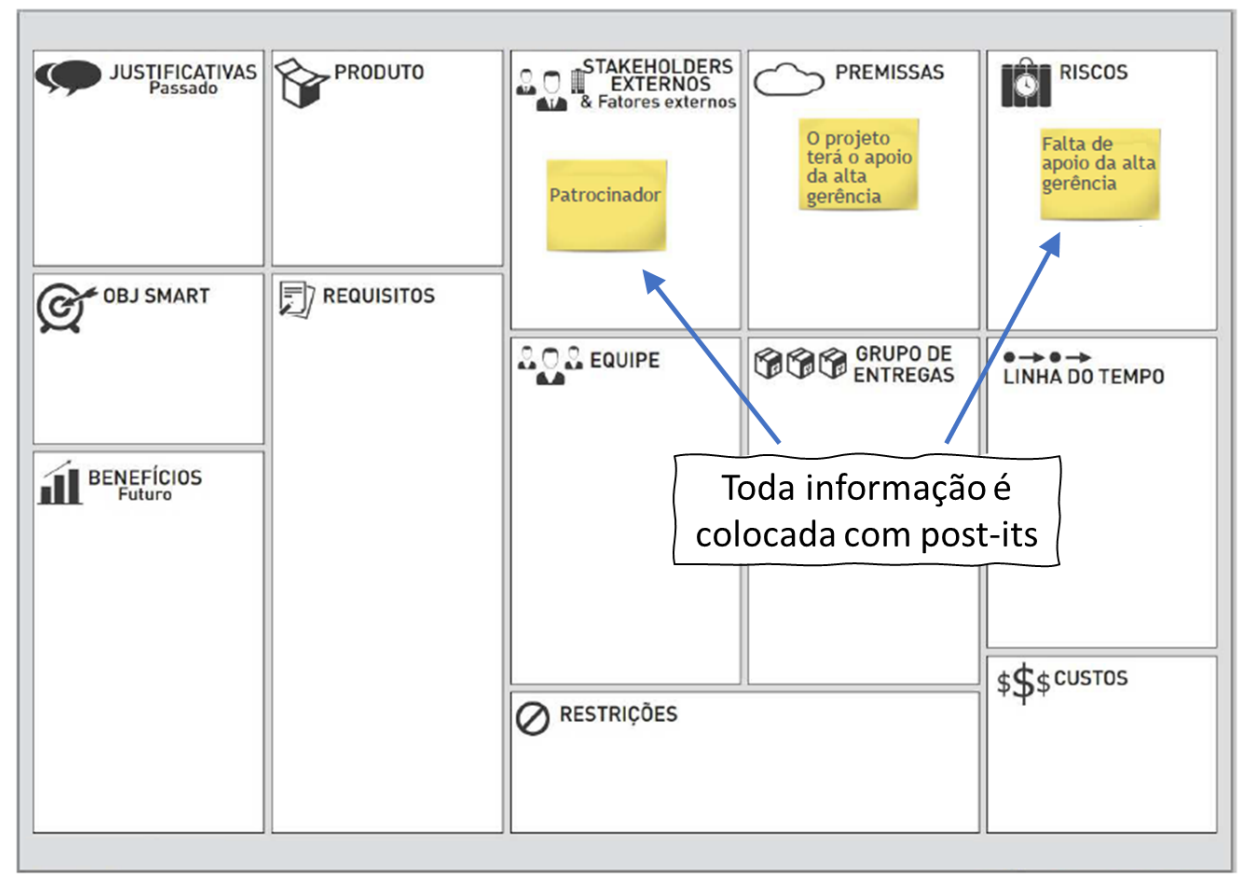

Figura 2: A tela (ou canvas) utilizada no PM Canvas (FINOCCHIO JUNIOR, 2013)

A tela (ou canvas) utilizada no PM Canvas, como pode ser observado na Figura 2, consta de 13 passos ou blocos que possuem um processo especial de preenchimento e de avaliação integrada, como veremos a seguir. 
A metodologia de concepção, apresentada em Finocchio Junior (2013) - Figura 3, indica a utilização do modelo baseada em quatro etapas, a $1^{\mathrm{a}}$ delas é conceber, quando utiliza-se o fluxo dos treze passos ou blocos do quadro para definir o projeto; a $2^{\mathrm{a}}$ é integrar, verificando a consistência entre os blocos concebidos; a $3^{\mathrm{a}}$ é resolver, quando são discutidos os problemas pelos stakeholders; e a $4^{\mathrm{a}}$ é compartilhar, ou comunicar as informações do projeto (em grupos).

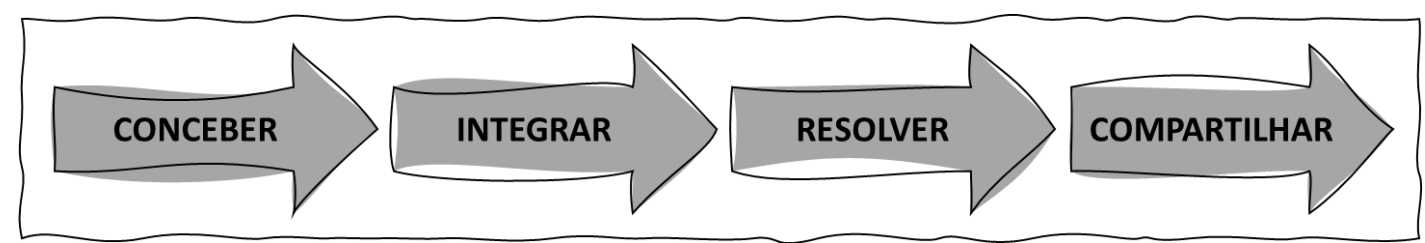

Figura 3: As 4 etapas da metodologia para trabalhar com o PM Canvas

\subsubsection{Conceber}

É a etapa na qual os treze blocos ou quadrantes do quadro são preenchidos, e eles vão compor o que se entende como o termo de abertura, a declaração de escopo e o plano do projeto (respondendo as perguntas do 5W2H: Por Quê, O Quê, Quem, Como, Quando, Onde e Quanto) - ver na Figura 4.

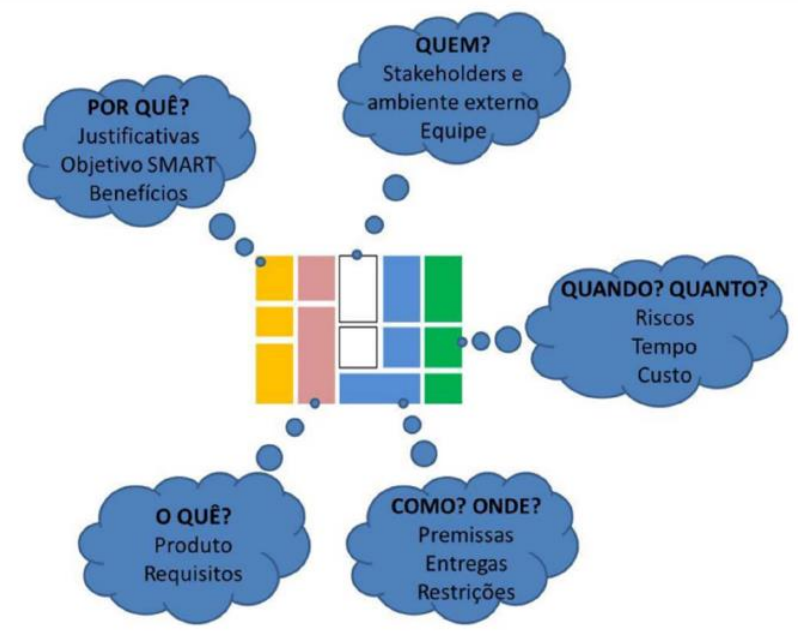

Figura 4: Correspondência do PM Canvas com o 5W2H (FINOCCHIO JUNIOR, 2013)

Na Figura 4 estão apresentados em cores diferentes os conjuntos de blocos ou quadrantes que se referem a cada uma das perguntas do método $5 \mathrm{~W} 2 \mathrm{H}$. O preenchimento da tela (ou canvas) segue uma sequência que atende os requisitos do método 5W2H, como está mostrado na Figura 5.

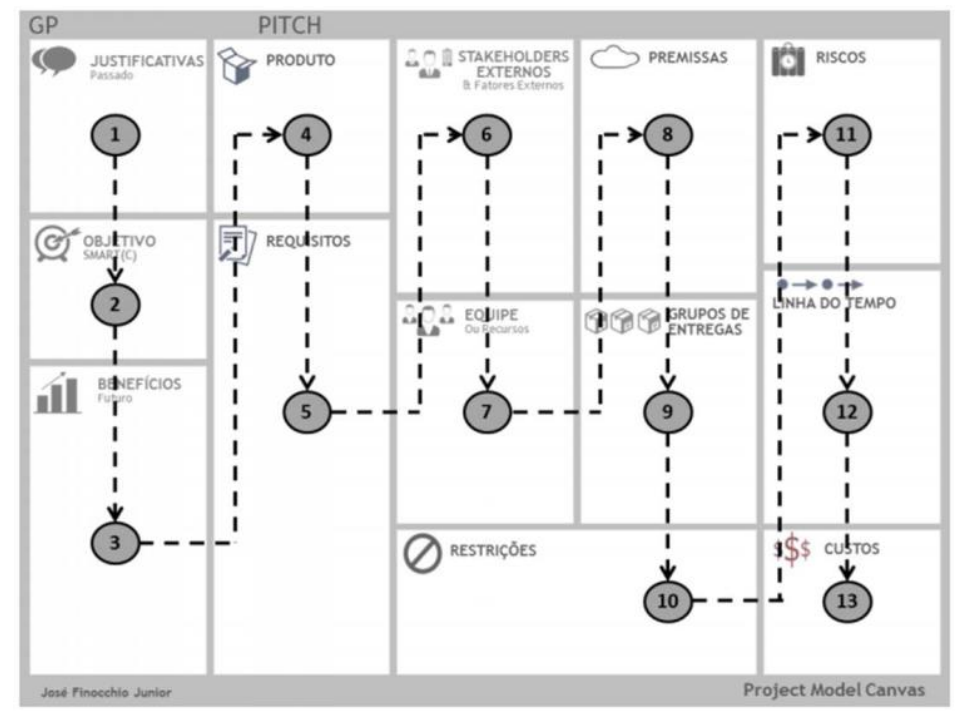

Figura 5: A Sequência de preenchimento da tela (ou canvas) (FINOCCHIO JUNIOR, 2013) 
Neste método, a pergunta Por Quê? é a mais importante, segundo Finocchio Junior (2013), pois define os valores que identificam os envolvidos no projeto. Via de regra, o que o patrocinador pergunta primeiro é Quando? e Quanto?. No PM Canvas estas duas perguntas são deixadas por último, propositadamente, pois elas só podem ser respondidas com certeza após se ter estabelecido outras definições. Como orientado rigorosamente no Guia PMBOK ${ }^{\circledR} 2018$ (PMI, 2018), a gestão eficaz de um projeto prevê os custos e estima o cronograma somente após se ter clareza sobre qual é a causa que o projeto defende, sobre qual é o produto ou serviço que será gerado, as pessoas alocadas para o trabalho, como as entregas serão feitas, etc. Os blocos no quadro estão dispostos em forma de fluxo e devem preferencialmente ser preenchidos na sequência já mostrada na Figura 5. Vamos agora passar o fluxo de preenchimento para avaliar que os requisitos do 5W2H estão contemplados pelos blocos.

\section{$\underline{\text { O Conjunto de Blocos do "Por quê": }}$}

Nas Justificativas, fala-se do passado e normalmente sobre o problema a ser resolvido, coisas ruins que precisam ser melhoradas, corrigidas, etc., pois os projetos são realizados buscando melhorias, e assim, todo projeto parte de um problema ou necessidade que precisa ser ser atendida.

O Objetivo SMART é uma descrição (que deve ser) sucinta do objetivo, que é a ligação entre o passado (o problema) e o futuro (a nova realidade, após a implementação do projeto) e sua importância é comprovada pelas justificativas. $\mathrm{O}$ termo SMART é um acrônimo criado por Peter Drucker, de Specific, Measurable, Accountable, Realistic, Timely, que traduzindo pode ser interpretado como um objetivo que seja específico, que pode ser medido na sua realização, que haja um responsável por obter os resultados, que deve ser realista e oportuno. Algumas literaturas, segundo Finocchio Junior (2013), também acrescentam um "C" ao final do termo, representando a delimitação de custo para se atingir o objetivo.

Os Benefícios representam a nova situação de futuro ou de coisas boas que serão alcançadas ao final do projeto. É a geração de valor ligada ao projeto, e pode inclusive ser aumento de receita, redução de custos, melhorias na qualidade de vida, etc. No PM Canvas, as Justificativas, o Objetivo SMART e os Benefícios - o conjunto dos três blocos representam o termo de abertura do projeto (TAP) e definem a razão pela qual ele deve ser realizado.

\section{$\underline{\text { O Conjunto de Blocos do "O quê": }}$}

O Produto é que será gerado pelo projeto, todo projeto deve gerar um produto ou um serviço, que vai possibilitar os benefícios pela sua utilização.

Os Requisitos são as características especiais que objetivam atender as necessidades e desejos do cliente ou, em alguns casos, dos stakeholders. Por definição, os requisitos fazem sempre referência ao produto e servem de base para se definir o escopo do projeto.

\section{O Conjunto de Blocos do "Quem":}

Os Stakeholders e Fatores Externos são as pessoas, empresas ou órgãoes envolvidos ou afetados pelo projeto, e também outros fatores que podem interferir diretamente no projeto. Esse grupo pode determinar a conclusão ou não de um projeto, a depender do seu interesse ou resistência. Os stakeholders mais importantes e sempre presentes em todos os projetos são o cliente, a quem receberá o produto, serviço ou resultado do projeto possuindo papel fundamental na formulação dos requisitos, e o patrocinador, que providenciará recursos para o projeto. Outros stakeholders conhecidos são os fornecedores de matéria prima, outros departamentos da organização, órgãos regulatórios, governo etc. Como fatores externos podemos citar o comportamento da economia, clima, fatores ambientais, etc.

A Equipe é formada pelos stakeholders internos, os recursos ou pessoas que estão subordinadas ao gerente do projeto, mesmo que temporariamente, para efeito deste projeto.

\section{$\underline{\text { O Conjunto de Blocos do "Como e Onde": }}$}

As Premissas são suposições arbitrárias a respeito do cenário de execução do projeto, relativamente incerto, e que geralmente fazem referência aos stakeholders e ao ambiente externo.

Os Grupos de Entregas são os produtos, serviços ou resultados, que sejam tangíveis, mensuráveis e verificáveis, que serão produzidos pelo projeto. Este bloco é uma simplificação das entregas do projeto, formando conjuntos de atividades. A ideia neste bloco não é excluir entregas, mas sim agrupá-las para melhor compreensão nesta fase. 
As Restrições são limitações que podem recair sobre o trabalho dos componetes da equipe do projeto e sobre as entregas que elas produzem, diminuindo a liberdade de opções. As restrições podem ser provocadas pelos stakeholders ou fatores externos ou pela própria característica do projeto ou do produto do projeto. Os itens Premissas, Entregas e Restrições - o conjunto dos três blocos - compõem a declaração de escopo do projeto (DEP).

\section{$\underline{\text { O Conjunto de Blocos do "Quando e Quanto": }}$}

Os Riscos são as incertezas relativas à execução do projeto podendo se configurar em ameaças ou em oportunidades, e as principais fontes de riscos são as premissas (derivadas dos stakeholders ou fatores externos) e as entregas do projeto. Os riscos podem ser divididos em Risco Global, relativo ao atendimento aos objetivos do negócio e Riscos Específicos que são possíveis ocorrências que possam afetar o trabalho no projeto. Toda incerteza considerável para o projeto precisa ser descrita quanto à sua causa ou fato gerador do evento sobre o projeto, o risco propriamente dito, ou seja, a falha ou oportunidade que caso ocorra afetará o projeto e o efeito ou impacto gerado nos objetivos do projeto. É aconselhável utilizar alguma forma de classificação da probabilidade de ocorrência de cada risco bem como de seus impactos no projeto para futura priorização dos riscos mais relevantes e daqueles que necessitarão de alguma resposta na fase de planejamento.

O Tempo é a linha de tempo ou de prazo em que se pretende produzir cada entrega. Ela representa o cronograma de alto nível ditado pelas entregas que são alocadas no tempo. A linha de tempo no PM Canvas, na verdade, é muito mais uma lista de compromissos do que um cronograma convencional, e representa o resultado de um julgamento sobre as informações que já estão disponíveis.

Os Custos são relativos à realização de cada entrega e, preferencialmente, devem ser alocados no tempo. Inicialmente pode ser uma estimativa global e grosseira para estimar a execução das entregas em conjunto ou de cada uma delas, mas ainda antes do início do projeto, é importante que se tenha o fluxo de despesas do projeto definido, para que eventuais necessidades econômicas não peguem de surpresa o patrocinador ou o financiador do projeto.

Ao final de um exercício da primeira etapa (conceber) da metodologia PM Canvas, o quadro deve apresentar algo parcido com a Figura 6.

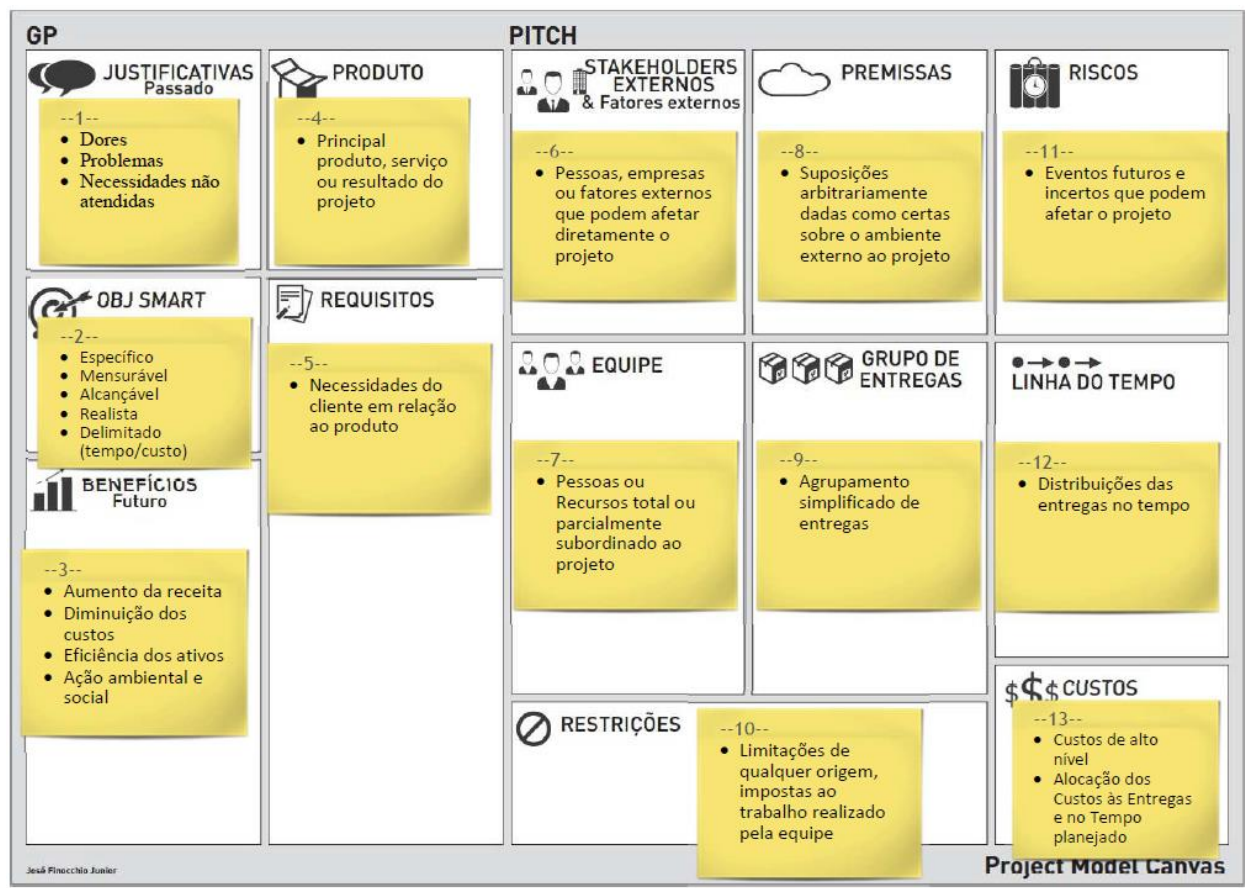

Figura 6: A tela (ou canvas) do PM Canvas prenchida (FINOCCHIO JUNIOR, 2013)

\subsubsection{Integrar}

A integração dos blocos no PM Canvas visa tornar o modelo mental representado pela tela (ou canvas) mais forte e é realizada entre os conjuntos de blocos, para verificar a consistência entre eles e também para respeitar a capacidade 
limitada do ser humano de lidar com "coisas" diferentes. A integração é melhor realizada por meio de amarrações de dois ou três blocos de cada vez, segundo Finocchio Junior (2013), verificando os seguintes grupos:

- no conjunto de blocos de Justificativa, Objetivo e Benefícios $\rightarrow$ deve-se atentar que as justificativas devem referenciar problemas que existem antes do projeto, e ser remetidas ao passado. E que os benefícios falam de um futuro, após a execução do projeto, sem os problemas. A ponte que transporta o cliente do passado ruim para um futuro melhor é a realização do objetivo do projeto, com os benefícios e a geração de valores;

- $\quad$ no conjunto de blocos de Produto e Requisito $\rightarrow$ deve-se atentar que o produto do projeto deve ser claro e que todas as necessidades do cliente devem ser traduzidas em requisitos;

- no conjunto de blocos de Stakeholders e Fatores Externos e Premissas $\rightarrow$ deve-se atentar em se pesquisar o ambiente de fora do controle da equipe de projeto, a procura de possíveis premissas para o projeto. Como poucas vezes temos certeza a respeito de todos os fatores em um projeto, para um bom planejamento, precisam ser dadas como certas algumas suposições do ambiente externo;

- $\quad$ no conjunto de blocos de Equipe, Grupos de Entregas e Restrições $\rightarrow$ deve-se atentar que as entregas devem ser produzidas pelos membros da equipe ou por alguém que seja subordinado ao gerente do projeto. Uma outra verificação que é importante de se realizar, é quanto à limitação imposta pelas restrições ao trabalho realizado pela equipe, e a influência destas restrições na produção das entregas;

- $\quad$ no conjunto de blocos de Grupo de Entregas, Premissas e Riscos $\rightarrow$ deve-se atentar que toda premissa do projeto gera um risco e, assim sendo, deve-se verificar se os principais riscos associados, que podem ser mapeados, às premissas e as entregas foram relacionados;

- $\quad$ no conjunto de blocos de Grupo de Entregas e Linha do Tempo $\rightarrow$ deve-se atentar que na espinha dorsal do cronograma, que devem ser as entregas. As entregas devem estar representadas na linha do tempo do MP Canvas em seus respectivos momentos;

- $\quad$ no Grupo de Grupo de Entregas, Linha do Tempo e Orçamento $\rightarrow$ deve-se atentar que o orçamento e o cronograma têm que ser subdivididos em uma mesma estrutura de entregas, e em uma mesma dimensão de tempo. Ainda, que ambos devem refletir as entregas delimitadas no Grupo de Entregas.

\subsubsection{Resolver}

Em um determinado ponto, no planejamento, algumas pessoas de paralisam diante de informações truncadas e outras já seguem em diante. Pensar em fazer um plano com todas as informações corretas, em alguns casos, pode parecer uma ilusão, segundo Finocchio Junior (2013). Esta etapa considera a discussão dos problemas pelos stakeholders e pode levar mais de tempo devido a possíveis complexidades envolvidas, principalmente quanto a opiniões divergentes. $\mathrm{O}$ intuito dessa etapa, Finocchio Junior (2013), é resolver os problemas que possam ter sido detectados nas fases passadas como, por exemplo:

- o projeto pode não gerar valor e não contribuir aos objetivos do negócio, como o aumento de receita, a redução de custo, melhoria de imagem, requisitos legais, etc.;

- o cliente pode não saber o que quer, ou alguns dos interessados no projeto não foram engajados nele, promovendo uma falha na lista de requisitos e, consequentemente, na definição do produto;

- $\quad$ os recursos podem não estar garantidos ou alocados para o projeto;

- $\quad$ o gerente do projeto pode não possuir autoridade ou influência para conduzi-lo, ou a equipe do projeto pode não conseguir identificar as entregas que precisam ser realizadas;

- pode ter havido negligência ou imperícia em se formular os riscos, e as premissas não foram aceitas pelos clientes ou os riscos foram considerados muito altos ou inconsistentes com os objetivos esperados;

- $\quad$ pode haver insegurança em relação à duração ou ao custo do projeto; 
- os parceiros de negócio podem não se integrar junto a equipe;

- pode faltar compromisso em sustentabilidade ambiental;

- pode existir resistência em relação ao projeto.

\subsubsection{Compartilhar}

As informações do projeto, a serem compartilhadas, também são comunicadas em grupos de blocos:

- o conjunto de blocos de Justificativa, Objetivo e Benefícios $\rightarrow$ define o propósito do projeto e representa o Termo de Abertura do Projeto (TAP), conforme descrito no Guia PMBOK ${ }^{\circledR} 2018$ (PMI, 2018);

- o conjunto de blocos de Produto, Requisito e Stakeholders $\rightarrow$ define os requisitos a serem entregues com a qualidade esperada para atender aos clientes e stakeholders;

- o conjunto de blocos de Stakeholders e Equipe do Projeto $\rightarrow$ representa a empresa, e está diretamente ligado ao projeto e é quem fornece subsídios como requisitos, informações, etc.;

- o conjunto de blocos de Grupos de Entregas, Premissas e Restrições $\rightarrow$ representa o escopo e o trabalho a ser realizado, e em que condições;

- o blocos de Riscos $\rightarrow$ é o conjunto das principais incertezas na execução do projeto;

- o conjunto de blocos de Grupos de Entregas, Linha do Tempo e Custos $\rightarrow$ representa a programação para a execução das tarefas do projeto, quando elas serão entregues e quanto irão custar.

O resultado final do PM Canvas também pode servir de base para gerar outros documentos, como apresentações, cronogramas e orçamentos, mais detalhados ou até mesmo um plano de projeto convencional.

\section{APLICAÇÕES DO PM CANVAS}

Nesta seção estão apresentadas as aplicações do PM Canvas em três situaçõs típicas de reabilitação de patologia das construções, uma reabilitação de pilates de concreto armado em estágio avançado de corrosão de armaduras, uma fachada em revestimento cerâmico que apresenta descolamento das peças, e um vazamento por falha na impermeabilização de uma piscina. Estas aplicações estão comentadas a seguir.

\subsection{Reabilitação de um conjunto de elementos estruturais}

A Figura 7 apresenta a tela do PM Canvas para a restauração de 28 pilares do pilotis de garagem de uma edificação, que apresentaram corrosão das armaduras. Cabe destacar desta tela a premissa de que haveria uma equipe especializada para a recuperação dos pilares, e na verdade a construtora contratada não possuia esta disponibilidade, logo, ou se assumiria um risco ao projeto ou se contrataria pessoal especializado.

Uma segunda discussão foi a respeito da avaliação real dos danos nos pilares, com auxílio de um técnico que realizaria análises de amostras in loco e em laboratório, pois o mesmo não estava provido até então de capacidade de realizar testes de penetração de cloretos.

A terceira discussão da reunião foi a respeito do escalonamento da seleção dos pilares (solicitação do cliente), de maneira a liberar o interior do pátio logo ao iniciar a obra. As discussões e enfrentamentos entre grupos de blocos resolveram todos os questionamentos da equipe do projeto, e a tela final do PM Cavas foi a apresentada na Figura 7.

Na Figura 7, as cinco entregas do PM Canvas foram, porteriormente, desdobradas em várias atividades que alimentaram o quadro do Kanban, para controle de execução da atividade. 


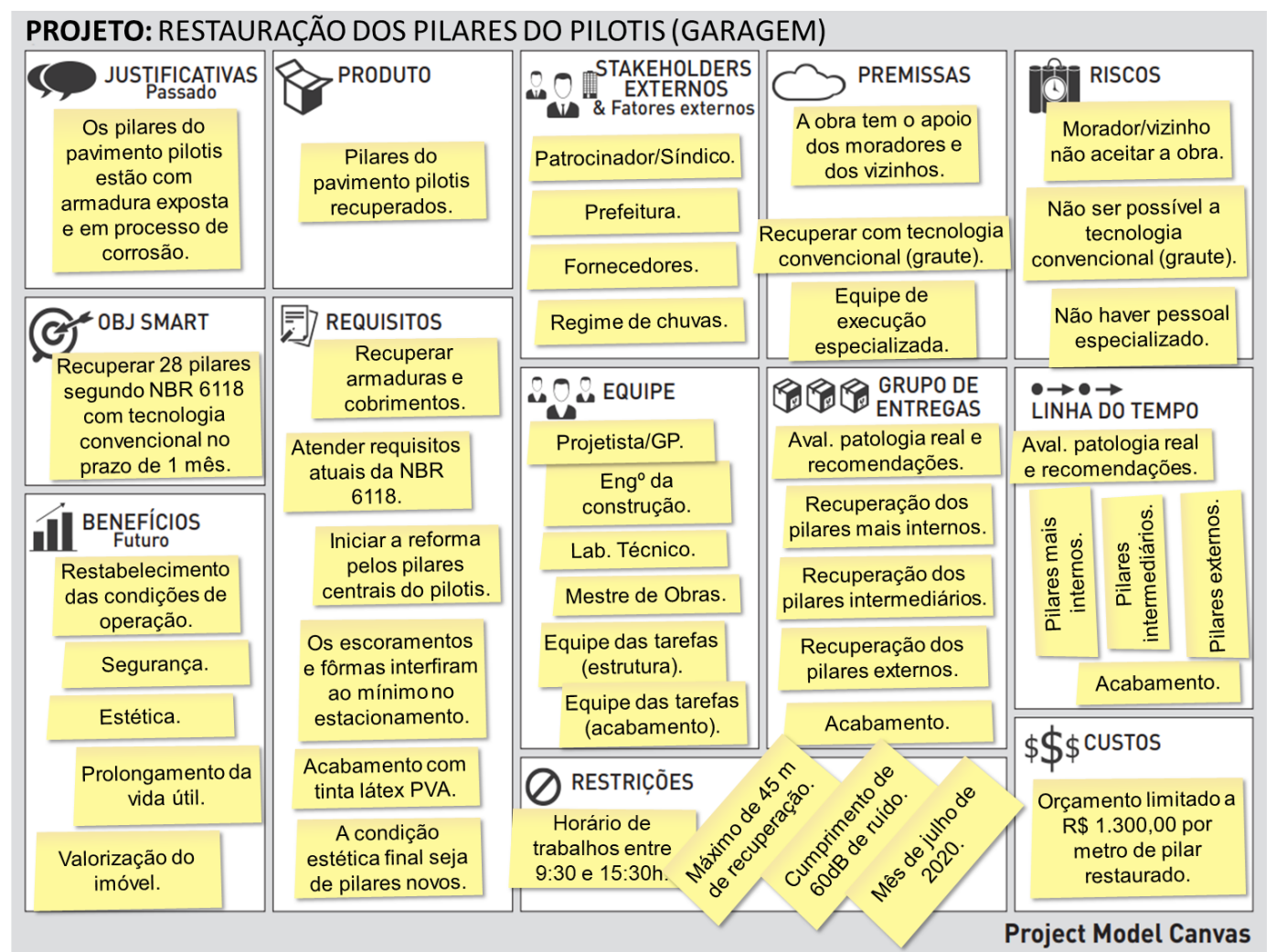

Figura 7: PM Canvas da Restauração dos Pilares do Pilotis

\subsection{Reabilitação de um descolamento de revestimento cerâmico em fachada}

A Figura 8 apresenta a tela do PM Canvas para a reabilitação do descolamento de revestimento cerâmico em fachada de uma edificação, que apresentou rompimento entre a argamassa de assentamento e o substrato. Na ocasião desta tela, foi discutido o requisito do cliente de que a fachada tivesse aspecto de nova, mesmo utilizando o reassentamento parcial de cerâmica, o que se tratou de um desafio ter disponível cerâmica e rejunte compatíveis com o revestimento já existente. Um segundo requisito do cliente foi não utilizar o andaime fachadeiro, por haver uma restrição da Prefeitura Municipal para a montagem deste tipo de equipamento naquela localidade. Um terceiro ponto, também discutido, foi a limitação de área de reassentamento em $20 \%$ da fachada, uma vez que foi o tamanho do lote da encomenda de cerâmica produzida sob medida. Como no item anterior, as discussões e enfrentamentos entre grupos de blocos resolveram os questionamentos da equipe do projeto, e a tela final do PM Cavas foi a apresentada na Figura 8.

Na Figura 8, ainda, as seis entregas do PM Canvas foram, porteriormente, desdobradas em várias atividades que alimentaram o quadro do Kanban, para controle de execução da atividade.

\subsection{Reabilitação de um vazamento em impermeabilização de piscina}

A Figura 9 apresenta a tela do PM Canvas para a reabilitação de vazamento da impermeabilização de piscina em uma edificação, que apresentou falha e permitiu a passagem de água. Nesta tela, foi discutido que a premissa de haver somente um ponto de vazamento poderia não estar correta, e que a empresa executora da impermeabilização dispusesse de recursos para maiores consertos. Um segundo ponto a ser discutido foi o processo de desmontagem/montagem das bombas da piscina (quais as melhores ocasiões e quais os recursos necessários) que, por solicitação do cliente, caberia também ao projeto e demandou a participação da empresa fornecedora das bombas. A terceira discussão realizada foi a respeito de uma restrição no projeto, de que não seriaa permitido o transporte de materiais e equipamentos pelos elevadores, ocasião em que se decidiu por alugar um dispositivo de elevação externo ao edifício. Foram realizadas as discussões e enfrentamentos entre grupos de blocos, que resolveram os questionamentos da equipe do projeto, e a tela final do PM Cavas foi a apresentada na Figura 9.

Na Figura 9, assim como nos casos anteriores, as cinco entregas do PM Canvas foram, porteriormente, desdobradas em várias atividades que alimentaram o quadro do Kanban, para controle de execução da atividade. 


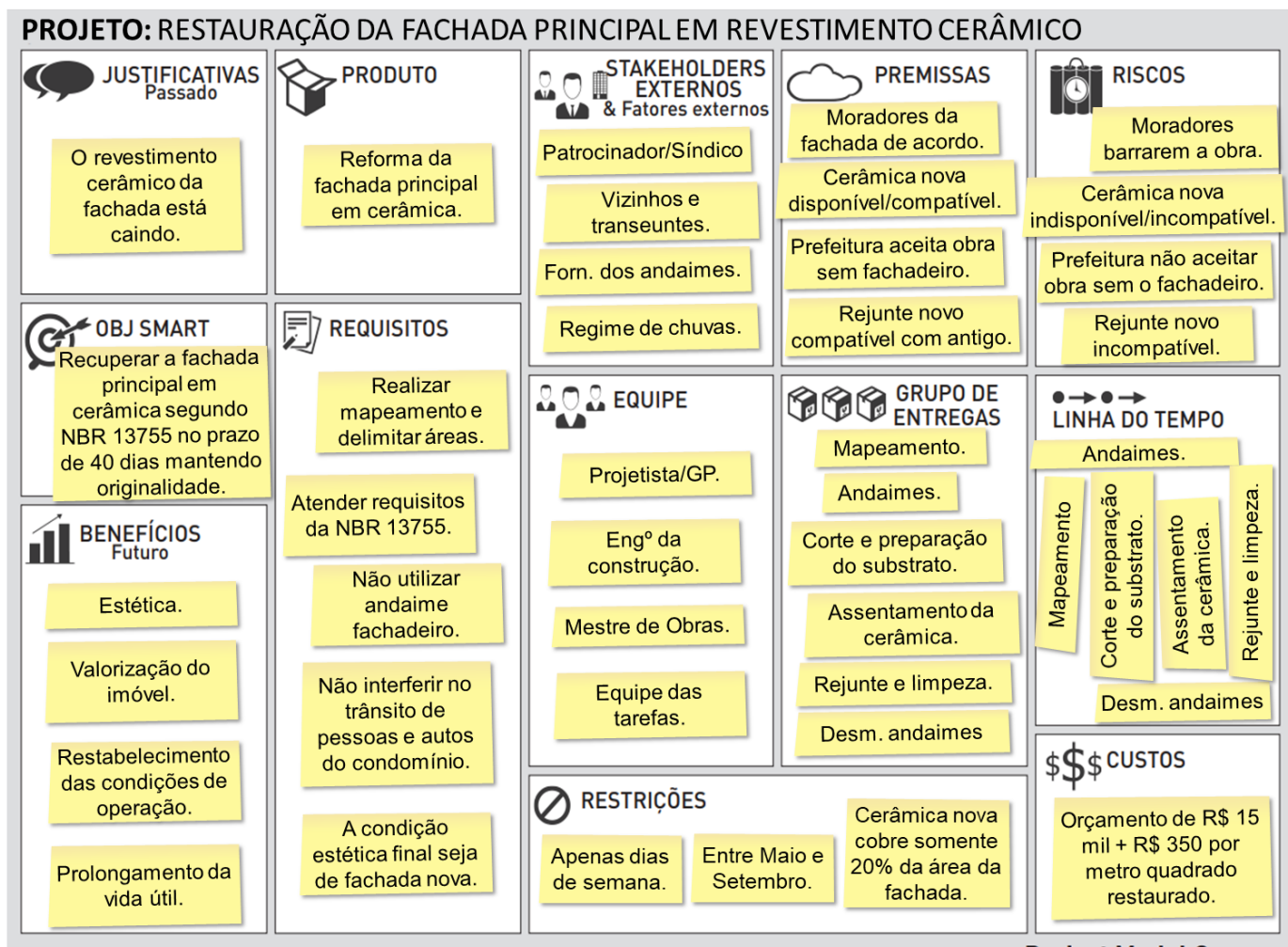

Figura 8: PM Canvas da Restauração da Fachada Principal em Revestimento Cerâmico

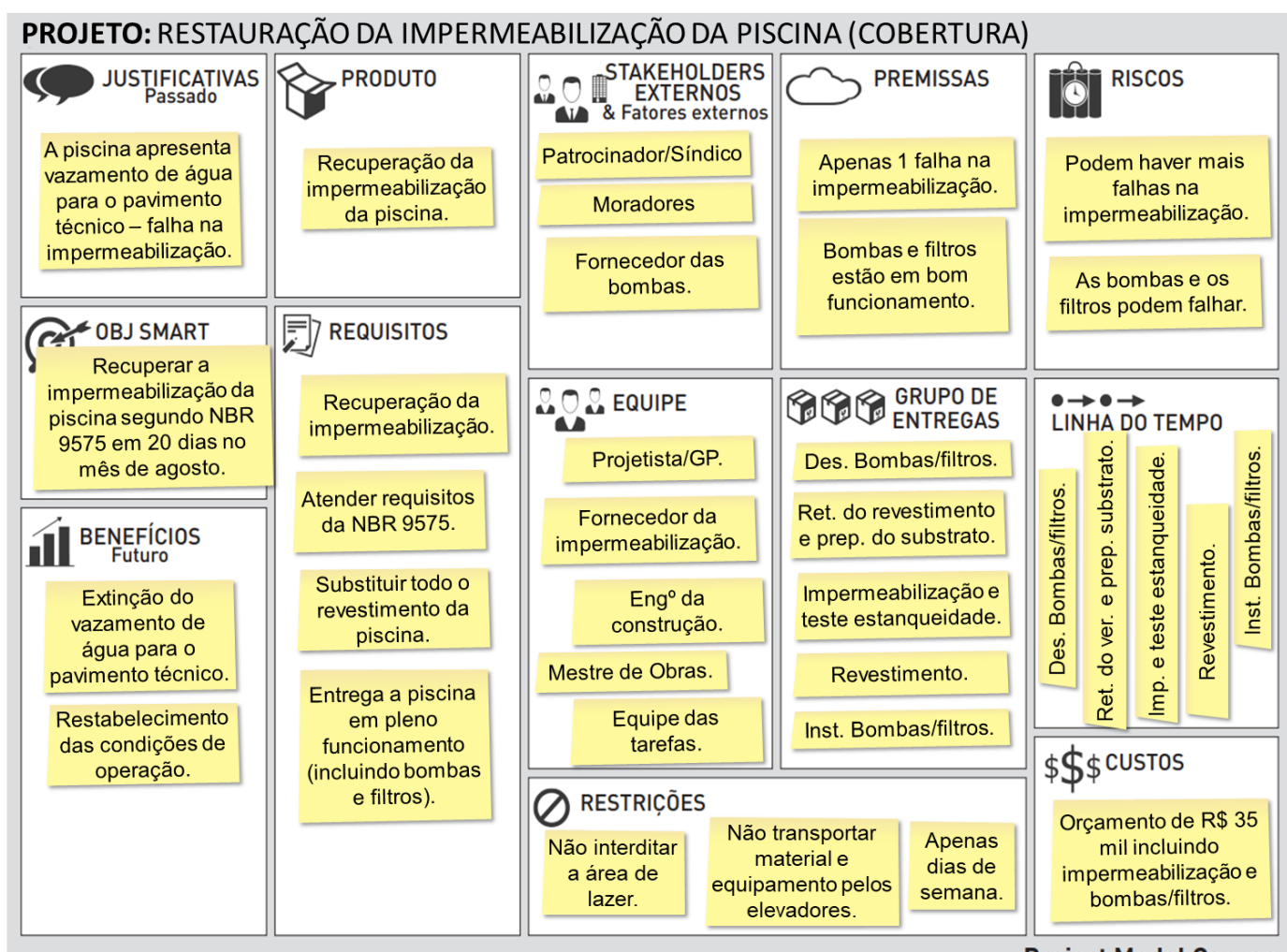

Figura 9: PM Canvas da Restauração da Impermeabilizção da Piscina

Project Model Canvas 


\section{INTEGRAÇÃO DO PM CANVAS COM O KANBAN}

O PM Canvas é uma ferramenta de planejamento que utiliza dos Métodos Visuais, e o Kanban, embora também utilize os mesmos Métodos, se trata de uma ferramenta de controle da execução. Por este motivo estas duas ferramentas se completam, primeiro fazendo o planejamento no PM Canvas e em seguida o controle da execução das entregas do projeto no Kanban. No quadro (ou canvas) do PM Canvas, o bloco Grupo de Entregas Estabelece as entregas do projeto, preferencialmente de maneira resumida para possibilitar o processo de planejamento facilmente gerenciável e, após encerradas as discussões, cada uma das entregas deve virar um conjunto de atividades no quadro do Kanban.

O quadro do Kanban é estruturado em três áreas: A Fazer, Fazendo e Feito. Nele as atividades progridem movendo-se as fichas da esquerda para a direita, e o que estabelece a velocidade é o limite de atividades simultâneas, que dita quais delas podem ser realizadas em cada etapa. Assim, uma atividade somente pode ser acrescentada em execução se uma outra atividade se encerrar, e assim cria-se um fluxo que possibilita a redução de estoque e o foco na atividade, acelerando a execução dos projetos. Os desdobramentos das entregas do PM Canvas para o controle da execução na obra, nos casos estudados, foram realizados com a utilização do Kanban, e não fazem parte do escopo deste trabalho.

\section{CONCLUSÃO}

Neste trabalho foram apresentados e discutidos três exemplos da aplicação do método PM Canvas em processos típicos de reabilitação de patologias das construções, uma restauração de pilares, um descolamento de revestimento cerâmico, e uma falha de impermeabilização de piscina. Em cada um deles foi possível observar o estabelecimento de um fluxo de ideias alimentado por informações preliminares do projeto, de maneira a subsidiar o atendimento aos requisitos do método 5W2H durante o preenchimento dos quadros, desde a concepção até o estabelecimento de cada uma das estregas do projeto. Como discutido de antemão, o PM Canvas é uma ferramenta que tem a capacidade de unir as pessoas, e acima de tudo colocar suas ideias em prática. Os quadros do PM Canvas preenchidos, como pôde ser visualizado, contemplam a amigabilidade, a maleabilidade, capacidade de facilmente ser modificados e rabiscados, permitindo perceber relações e visualizar problemas estruturais entre as partes do projeto. As telas finais possibilitam, após a resolução dos problemas, observar o retrato visual e conciso do projeto a ser realizado, possibilitando uma visão clara e rápida que permite, em cada entrega, identificar o que fazer e como chegar até lá.

\section{REFERÊNCIAS}

CAMARGO, R.A. PM Visual - Project Model Visual: Gestão de Projetos Simples e Eficaz. $2^{\text {a }}$ Edição. Ed. Saraiva. 216p. São Paulo. 2019.

CIERCO, A.A.; MENDES, J.R.B.; MONAT, A.S.; NASCIMENTO, F.P. Gestão de Projetos. FGV Management Escola de Administração da Fundação Getúlio Vargas. Editora FGV. 160p. Rio de Janeiro. 2011.

FINOCCHIO JUNIOR, J. Project Model Canvas: Gerenciamento de Projetos Sem Burocracia. Elsevier. Rio de Janeiro. 230p. 2013.

FINOCCHIO JUNIOR, J. Como integrar PM Canvas ao Kanban. Youtube, 23 jul. 2018. Disponível em <https:// www.youtube.com/watch?v=zAJnJMPBRSk>. Acesso em: 10 dez. 2019. 2018.

HARVARD BUSINESS REVIEW. HBR Guide to Project Management (HBR Guide Series). $2^{\text {nd }}$ Edition. Harvard Business Review Press. 192p. Boston, Massachusets. USA. 2015.

OSTERWALDER, A. Business Model Generation. Inovação em Modelos de Negócios. 300p. Rio de Janeiro, 2011.

PROJECT MANAGEMENT INSTITUTE (PMI). Um Guia do Conhecimento em Gerenciamento de Projetos (Guia PMBOK $\left.^{\circledR}\right)-6^{a}$ Edição. Project Management Institute, Inc. Filadélfia, Pensilvânia. USA. 756p. 2018.

TEIXEIRA, J.M.; MERINO, E. Gestão visual de projetos: um modelo voltado para a prática projetual. Strategic Design Research Journal, 7(3): 123-132. September-December. 2014.

VARGAS, R.V. Gerenciamento de Projetos. 9ª Edição. Editora Brasport. 288p. São Paulo. 2018.

VERONEZ. M. Uma Proposta de Metodologia de Projeto a ser Aplicada nos Processos de Reabilitação das Manifestações Patológicas. Monografia (Especialização em Enga de Patologia das Construções). Faculdade UnyLeya. 87p. Rio de Janeiro. 2019. 